\title{
EDITORIAL
}

\section{Impairment of gas exchange in liver cirrhosis}

\author{
P.D. Wagner
}

The paper in this issue by CRAWFORD et al. [1] addresses a problem that has vexed clinicians and physiologists for many years: In cirrhosis, the presence and mechanisms of hypoxaemia, usually more severe in the upright posture, and without evidence of classical lung disease, such as obstructive or restrictive syndromes. Ever since abnormally dilated pulmonary blood vessels were first identified in such patients [2], studies have focused on the obvious potential connection between such functional shunts and hypoxaemia [3-10]. CRAWFORD et al. have used two separate techniques to assess gas exchange in a single patient: 1) the multiple inert gas elimination technique (MIGET, [11]) which quantifies ventilation/perfusion $\left(V^{\prime} \mathrm{A} / Q^{\prime}\right)$ relationships, right to left pulmonary and cardiac shunts, and, indirectly, diffusion limitation of $\mathrm{O}_{2}$ exchange and 2) intravenous injection of radio labelled particles to assess their passage through the lungs as a means to quantify flow through the abnormal, dilated vessels.

In summary, Crawford's results in a patient breathing room air suggest the existence of $\mathrm{O}_{2}$ diffusion limitation plus $V^{\prime} \mathrm{A} / \mathrm{Q}^{\prime}$ mismatch with shunts. Two additional observations are especially intriguing: 1) the shunt computed from labelled particle retention in the lungs was much greater than the functional shunt for $\mathrm{O}_{2}$ and 2) breathing $100 \% \mathrm{O}_{2}$, the functional shunt for $\mathrm{O}_{2}$ was considerably less than that predicted from the MIGET data at the same time.

While neither a broad review of the topic nor a full discussion of this study are possible within the confines of an editorial, several specific issues in Crawford's paper deserve discussion.

\section{Causes of hypoxaemia in this patient}

The patient is a moderate smoker with mild airway obstruction (forced expiratory volume in one second to forced vital capacity ratio) (FEV1/FVC) 90\% predicted and evidence of moderate restrictive lung disease total lung capacity (TLC), vital capacity $(\mathrm{VC})=78 \%$ of predicted, transfer factor across the lung for carbon monoxide $T \mathrm{~L}, \mathrm{CO}=34 \%$ of predicted). The $T \mathrm{~L}, \mathrm{CO}$ reduction is excessive for the volume and flowrate abnormalities, and compares to a $T \mathrm{~L}, \mathrm{CO}$ of about $60 \%$ of predicted for the cirrhotic patients of EDELL [8] whose TLC values were $100 \%$ of predicted.

As shown by Agustí et al. [12], diffusion limitation (in another disease, namely, interstitial fibrosis) occurs

University of California, San Diego, Department of Medicine, 9500 Gilman Drive, La Jolla, CA 92093-0623 even at rest when TL,CO falls below about $50 \%$ of predicted, and Agustí's patients did not have pulmonary vascular malformations. Perhaps the subject of Crawford's study has lung disease in addition to vascular malformations, and both contribute to the hypoxaemia.

\section{Interpretation of radiolabelled particle distribution}

The authors used albumin aggregates whose diameters were stated to range from $15 \mu \mathrm{m}$ to $50 \mu \mathrm{m}$. Assuming radioactivity relates to particle mass, not diameter, $50 \mu \mathrm{m}$ particles would be 37 times hotter than $15 \mu \mathrm{m}$ particles $\left((50 / 15)^{3}=37\right)$. If the abnormal vascular channels at their narrowest exceeded $50 \mu \mathrm{m}$ diameter, this inhomogeneity of size may have posed no problem. If any were less than $50 \mu \mathrm{m}$ but greater than $15 \mu \mathrm{m}$, the hottest particles would have been preferentially caught in the lungs. Thus, without knowing the anatomy of the abnormal vessels or the distribution of particle sizes between 15 and $50 \mu \mathrm{m}$, there is a potential interpretative limitation on using the radioactive particle data to quantitatively assess the vascular shunts. Of interest, this would if anything underestimate the shunt, already computed to be about $40 \%$.

\section{Interpretation of inert gas (MIGET) data}

Several issues arise. The authors argue that the room air data suggest diffusion limitation for $\mathrm{O}_{2}$ because the inert gases, generally considered to be invulnerable to diffusion limitation, predict a higher arterial oxygen tension $\left(\mathrm{Pa}_{\mathrm{a}} \mathrm{O}_{2}\right)$ than was measured [13]. This result agrees with EDELL $e t$ al. [8] and CASTAING and MANIER [14] (and many other MIGET-based studies in other settings). The low TL,CO is consistent with this. However, whether the dilated vascular channels are the site of this limitation is uncertain. It is hard to imagine how these channels reduce total lung TL,CO to $34 \%$ of predicted if indeed the alveolar parenchyma is otherwise normal. Thus, hypothetically abnormal parenchyma could explain the observations rather than limited $\mathrm{O}_{2}$ exchange across the abnormal vessels. There are thus two competing hypotheses and it would seem that they cannot be distinguished from the present data.

The $100 \% \mathrm{O}_{2}$ breathing data are particularly intriguing and the higher measured-than-MIGET-predicted $\mathrm{Pa}_{\mathrm{a}} \mathrm{O}_{2}$ is used by the authors as evidence of diffusion limitation of the inert gases, especially the least soluble gas, sulphur hexafluoride (SF6). However, while the diffusion 
coefficient of a gas in blood indeed depends on the partition coefficient (as they state), the time to reach diffusion equilibration between blood and alveolar gas additionally depends on blood capacitance for the gas. This is also proportional to the partition coefficient. These two dependencies therefore cancel out the effects of partition coefficient on diffusion equilibration, leaving only molecular weight (MW) as the factor separating the six MIGET gases [15]. Because SF6 has a high MW (146) while the next gas in solubility, ethane, has a MW of only 30, a discrepancy in inert gas elimination patterns will develop as soon as inert gas diffusion limitation becomes physiologically recognizable. Specifically, the residual sum of squares (RSS) must begin to rise to abnormal levels as SF6 (and/or enflurane, the other MIGET gas of high MW) are preferentially retained in the blood. Such has been indeed noted in several studies [16-18]. Given the very low (i.e., normal) RSS values in the present paper, the mechanism of inert gas diffusion limitation is therefore unlikely. What other possibilities can be imagined? Two come to mind. First, systematic errors in the overall collection of measured variables could be at fault (random errors are not the explanation given the consistent data of table 1). Coexistence of very low $V^{\prime} \mathrm{A} / Q^{\prime}$ regions with true shunts poses a resolution problem for MIGET due to difficulty in their precise separation: systematic overestimation of shunt with corresponding underestimation of low $V^{\prime} \mathrm{A} / Q^{\prime}$ areas would reduce predicted arterial $P \mathrm{a}, \mathrm{O}_{2}$ and thus could explain the data. This could be specific to this individual patient for in EDELL's work [8], measured and predicted $\mathrm{Pa}, \mathrm{O}_{2}$ on $100 \% \mathrm{O}_{2}$ agreed closely. A second possibility is that there may be lung regions sufficiently poorly ventilated that during $100 \% \quad \mathrm{O}_{2}$ breathing, no expired gas leaves those alveoli despite the continued existence of some inspired ventilation. These regions would be at or below the critical inspired ventilation/ perfusion ratio, $V^{\mathrm{I}} \mathrm{I} / Q^{\prime}$, of DANTZKER et al. [19] a value commonly around 0.08 . Such would result in continued oxygenation of the end capillary blood, but inert gases would not be eliminated, the MIGET data thus indicating a shunt with an unexpectedly high measured $P \mathrm{a}, \mathrm{O}_{2}$. In both of these possibilities (discrimination of shunt from low $V^{\prime} \mathrm{I} / Q^{\prime}$ areas and regions of lower than critical $\left.V^{\prime} \mathrm{I} / Q^{\prime}\right)$, the RSS would not be abnormally high, unlike the situation of inert gas diffusion limitation.

\section{Reconciling MIGET and radiolabelled particle data}

No method currently used can guarantee that the particular lung regions responsible for transmission of intravenously injected particles, the abnormal vessels, are those responsible for abnormal gas exchange data. It is conceivable even if unlikely that the abnormal channels both oxygenate the blood, and eliminate inert gases adequately and that the gas exchange problems originate elsewhere, at least in part. This makes the quantitative difference between the particle-determined shunt $(\sim 40 \%)$ and that based on gas exchange ( $\sim 20-25 \%)$ more difficult to assess but accordingly less problematic to accept. What then can be concluded from Crawford's paper? 1. Their patient has hypoxaemia from a combination of shunt, $V^{\prime} \mathrm{A} / Q^{\prime}$ mismatch and $\mathrm{O}_{2}$ diffusion limitation. Lung disease remains a possible contributing factor, even while vascular malformations are shown to exist.

2. Inert gas diffusion limitation should greatly increase the MIGET residual sum of squares, which was not seen. Other explanations might be considered, as discussed.

3 . The radioactively labelled particles indicate a larger shunt than do gas exchange data, but reconciling these differences is not currently possible.

For the most part, these conclusions fit with similar, prior observations, highlight the complexity of hypoxemia caused by cirrhosis of the liver, and show that we still do not have the tools to fully understand its basis.

\section{References}

1. Crawford ABH Regnis J, Laks L, Donnelly P, Engel LA, Young IH. Pulmonary vascular dilatation and diffusiondependent impairment of gas exchange in liver cirrhosis. Eur Respir J 1995; 8: 1913-1919.

2. Rydell R, Hoffbauer FW. Multiple pulmonary arteriovenous fistulas in juvenile cirrhosis. Am J Med 1956; 21: 450-460.

3. Wolfe JD, Tashkin DP, Holly FE, Brachman MB, Genovesi MG. Hypoxemia of cirrhosis. Detection of abnormal small pulmonary vascular channels by a quantitative radionuclide method. Am J Med 1977; 63: 746-754.

4. Stanley NN, Williams AJ, Dewar CA, Blendis LM, Reid L. Hypoxia and hydrothoraces in a case of liver cirrhosis: correlation of physiological, radiographic, scintigraphic and pathological findings. Thorax 1977; 32: 457-471.

5. Genovesi MG, Tierney DF, Taplin GV, Eisenberg H. An intravenous radionuclide method to evaluate hypoxemia caused by abnormal alveolar vessels: limitation of conventional techniques. Am Rev Respir Dis 1976; 114: 59-65.

6. Davis HX, Scwhartz DJ, Lefrak SS, Susman N, Schainker BA. Alveolar-capillary oxygen disequilibrium in hepatic cirrhosis. Chest 1978; 73: 507-511.

7. Mélot C, Naeije R, Dechamps P, Hallemans R, Lejeune P. Pulmonary and extrapulmonaly contributors to hypoxemia in liver cirrhosis. Am Rev Respir Dis 1989; 139: 632640.

8. Edell ES, Cortese DA, Krowka MJ, Rehder K. Severe hypoxemia and liver disease. Am Rev Respir Dis 1989; 140: 1631-1635.

9. Thorens JB, Junod AF. Hypoxaemia and liver cirrhosis: a new argument in favour of a "diffusion-perfusion defect". Eur Respir J 1992; 5: 754-756.

10. Rodríguez-Roisin R, Roca J, Agustí AGN, Mastai R, Wagner PD, Bosch J. Gas exchange and pulmonary vascular reactivity in patients with liver cirrhosis. Am Rev Respir Dis 1987; 135: 1085-1092.

11. Evans JW, Wagner PD. Limits on $V^{\prime} \mathrm{A} / Q^{\prime}$ distributions from analysis of experimental inert gas elimination. $J$ Appl Physiol 1977; 42: 889-898.

12. Agustí AGN, Roca J, Gea J, Wagner PD, Xaubet A, Rodríguez-Roisin R. Mechanisms of gas exchange impairment in idiopathic pulmonary fibrosis. Am Rev Respir Dis 1991; 143: 219-225.

13. Wagner PD, West JB. Ventilation-perfusion relationships. In: West J B (eds) Ventilation, Blood Flow and Diffusion. New York, Academic Press, 1980; pp. 219-262.

14. Castaing Y, Manier G. Haemodynamic disturbances and 
$V^{\prime} \mathrm{A} / Q^{\prime}$ matching in hypoxemic cirrhotic patients. Chest 1989; 96: 1064-1069.

15. Wagner PD. Diffusion and chemical reaction in pulmonary gas exchange. Physiol Rev 1977; 57: 257-312.

16. Truog WE, Hlastala MP, Standert TA, McKenna HP, Hodson WA. Oxygen-induced akeration of ventilationperfusion relationships in rats. J Appl Physiol 1979; 47: 1112-1117.

17. Hsia CCW, Herazo LF, Ramanathan M, Johnson Jr. RL,
Wagner PD. Cardiopulmonary adaptations to pneumonectomy in dogs II. $V^{\prime} \mathrm{A} / Q^{\prime}$ relationships and microvascular recruitment. J Appl Physiol 1993; 74: 1299-1309.

18. Johnson EC, Erickson BK, Podolsky A, et al. Effects of a perfluorocarbon emulsion for enhanced oxygen solubility on hemodynamics and oxygen transport in dogs. J Appl Physiol 1995; (In Press).

19. Dantzker DR, Wagner PD, West JB. Instability of lung units with low $V^{\prime} \mathrm{A} / Q$ ratio during $\mathrm{O}_{2}$ breathing. J Appl Physiol 1975; 38: 886-895. 